\title{
Picture superiority in conceptual memory: Dissociative effects of encoding and retrieval tasks
}

\author{
CHANDAN J. VAIDYA and JOHN D. E. GABRIELI \\ Stanford University, Stanford, Califormia
}

\begin{abstract}
We examined the role of encoding processes for picture superiority in explicit and conceptualimplicit memory. The nature of encoding instruction (naming or semantic categorization) yielded dissociative effects on picture and word memory on one explicit test, category-cued recall, and two conceptual-implicit tests, category-cued generation and category-cued verification. Category-cued recall was greater for pictures than for words following naming, but it did not differ for pictures and words following semantic categorization. Category-cued generation priming was greater for pictures than for words following naming, but it was greater for words than for pictures following semantic categorization. In contrast, category-cued verification priming did not differ for pictures and words following either naming or semantic categorization. Thus, picture superiority can be eliminated or reversed depending on the type of conceptual encoding task and conceptual-retrieval test.
\end{abstract}

Pictures are usually remembered far better than words (Borges, Stepnowsky, \& Holt, 1977; Madigan, 1983; Paivio, Rogers, \& Smythe, 1968; Scarborough, Gerard, $\&$ Cortese, 1979). This picture superiority effect is observed on tests of explicit memory that require conscious recollection of past experience. One explanation of this effect is that pictures engage greater conceptual elaborative processing than words. In general, explicit retrieval is enhanced under conditions of conceptual elaboration, such as semantic (vs. nonsemantic) levels of processing and generation (vs. reading) of study phase words (Craik \& Lockhart, 1972; Slamecka \& Graf, 1978). Pictures may engage greater elaborative processing because they may be associated with more symbolic codes in conceptual memory (verbal and imaginal; Paivio, 1986), or with a more distinctive imaginal code (Nelson, 1979), than words. Thus, the mnemonic advantage of pictures over words is believed to stem from encoding differences between the two symbolic formats.

Few investigations of the picture superiority effect, however, have examined directly the role of encoding processes. Retrieval processes, on the other hand, have received considerable research attention. On tests of explicit retrieval, picture superiority occurs regardless of the nature of retrieval cues. Picture superiority occurs on free recall, in picture recognition, and even when the retrieval cue is dissimilar to the picture (i.e., auditory or visual word cues on recognition tests). In contrast, on tests

This research was supported by NIH Grants AG11121 and MH 53673. We thank Brenda Allcorn, Tanya Laidman, Sristi Nath, and Krista Pelisari for assistance with data collection. Correspondence should be addressed to C. J. Vaidya, 306A White-Gravenor, Department of Psychology, Georgetown University, Washington, DC 20057 (e-mail: civ2@georgetown.edu). of implicit retrieval, the nature of the retrieval cue determines whether pictures yield superior memory. Implicit tests make no reference to past experience, but measure its effects as priming, a facilitation in speed, accuracy, or bias in performance on a subsequent task (Graf \& Schacter, 1985). When such tests emphasize perceptual analysis, priming is greater for pictures than for words only when pictures appear as retrieval cues (Durso \& Johnson, 1980; Lachman \& Lachman, 1980; Park \& Gabrieli, 1995; Srinivas, 1993; Warren \& Morton, 1982; Weldon \& Roediger, 1987). Priming is greater for words than for pictures on tests that require identification of briefly exposed words or completion of word fragments or word stems (Kirsner, Milech, \& Stumpfel, 1986; Rajaram \& Roediger, 1993; Weldon \& Roediger, 1987; Winnick \& Daniel, 1970). These findings are consistent with the general principle of transfer appropriate processing that memory is enhanced to the extent that encoding and retrieval processing overlap (Morris, Bransford, \& Franks, 1977). Thus, perceptual processes engaged at study are reengaged during perceptual-implicit retrieval and result in picture or word superiority, depending on the stimulus format at study.

Some implicit tests emphasize conceptual analysis, such as category-cued generation, which requires participants to produce exemplars of a specified semantic category, and word-cued association, which requires production of free association responses to words. Category-cued generation priming is enhanced by conceptual elaborative encoding, such as semantic levels of processing and generation from semantic cues (Hamann, 1990; Srinivas \& Roediger, 1990; Vaidya et al., 1997). Word-cued association priming, however, is often unaffected by conceptual encoding (Schacter \& McGlynn, 1989; Vaidya et al., 1997; but see Weldon \& Coyote, 1996). On both tests, 
however, neither picture nor word superiority has been observed (Weldon \& Coyote, 1996). The absence of picture superiority during conceptual-implicit retrieval seems to go against the principle of transfer appropriate processing: If pictures engage greater conceptual elaborative processing, as they are believed to on the basis of findings from explicit retrieval tests, then test phase recapitulation of those processes during conceptual-implicit retrieval ought to yield more priming for pictures than for words. Priming on both tests was sensitive to conceptual elaborative encoding in Weldon and Coyote's studies because priming was greater following semantic than nonsemantic levels of processing of words that were the names of picture stimuli. Failure to obtain picture superiority on conceptual-implicit tests that were sensitive to conceptual encoding suggests that the explanation for the picture superiority effect in explicit retrieval is not rooted in conceptual elaboration at encoding.

The importance of encoding processes in mnemonic superiority is highlighted by findings showing reversal or elimination of the picture superiority effect on recognition memory. In most studies reporting picture superiority, participants either view or name pictures and words passively. However, when encoding instructions specify the type of processing to be carried out, pictures can lose their mnemonic advantage. Pictures were remembered better than words following naming (Durso \& Johnson, 1980; E. R. Smith \& Magee, 1980). Words were remembered better than pictures following imagery instructions (Durso \& Johnson, 1980). Pictures and words were remembered equally well following semantic categorization (E. R. Smith \& Magee, 1980). Therefore, pictures and words can be rendered mnemonically equivalent or nonequivalent in explicit retrieval, depending on encoding conditions.

One explanation for the above findings can be found in studies showing that access to the conceptual information relevant to an encoding task varies as a function of stimulus format. Participants were slowest to name pictures, faster to semantically categorize words and pictures, and fastest of all to name (read) words (Potter \& Faulconer, 1975; E. R. Smith \& Magee, 1980). The observed pattern of recognition memory following these encoding conditions suggests that explicit retrieval was related to the amount of processing effort exerted during encoding. Thus, for pictures, naming was slower than categorization and yielded superior recognition memory than that after categorization. For words, categorization was slower than naming and yielded superior recognition memory than that after naming. Words and pictures were categorized at similar speeds and yielded comparable levels of recognition memory. Thus, it was the interaction between encoding instruction and stimulus format that determined subsequent mnemonic performance.

If conceptual processing of words and pictures varies as a function of encoding task, then conceptual implicit and explicit memory should be driven by encoding processes rather than stimulus format per se. This prediction, however, was not supported by Weldon and Coyote's (1996) findings. They found that category-cued generation priming did not differ for pictures and words. One possible reason for the absence of priming differences could be that their procedures did not control encoding processes. In that study, encoding instructions required participants to "pay close attention" to words and pictures on the screen. Such open-ended instructions could evoke a variety of encoding strategies (e.g., naming, categorizing) in participants that vary in the extent of conceptual processing. On the basis of results reviewed earlier, Weldon and Coyote's open-ended instructions could fail to capture picture or word superiority because both effects would sum to null if some participants named while others categorized. Cued recall and free recall, however, were superior for pictures relative to words. Thus, in contrast to implicit retrieval, it appears that explicit retrieval, at least on recall tests, may yield picture superiority regardless of the encoding instruction.

Thus, several questions remain regarding picture superiority in conceptual-implicit and explicit retrieval: (1) What encoding processes, if any, lead to picture superiority in conceptual-implicit retrieval? (2) Do unitary processes mediate picture superiority in different conceptual-implicit measures? Weldon and Coyote (1996) included only conceptual-implicit tasks that required generation of target items, category-cued generation, and word association. Past research suggests that priming on such generation measures is dissociable from that on conceptual priming tests, such as category-cued verification, that do not require generation but rather require mere identification of presented target items (Gabrieli et al., 1999; Light, Prull, \& Kennison, 2000; Vaidya et al., 1997). (3) Do unitary processes underlie picture superiority in conceptual-implicit and explicit retrieval? Weldon and Coyote's findings suggest that they do not. It is unknown whether these findings will extend to memory following different encoding processes. The present study addressed these questions.

In Experiment 1, words and pictures were studied with two encoding instructions, naming and semantic categorization. Memory was examined by a conceptual-implicit test, category-cued generation, and an explicit retrieval test, category-cued recall. The two tests were matched in the nature of test cues and differed only in the implicit and explicit retrieval instructions. In Experiment 2, we examined priming for words and pictures following naming and semantic categorization on another conceptualimplicit test, category-cued verification.

\section{EXPERIMENT 1}

Category-cued generation priming and category-cued recall were examined following either naming words and pictures or categorizing (manufactured vs. natural) words and pictures in eight separate groups of participants. For cued recall, on the basis of Weldon and Coyote's (1996) findings, performance should be greater for pictures than 
Table 1

Mean (and Standard Deviation) Percentage of Studied and Nonstudied Target Items Produced on Category-Cued Generation and Category-Cued Recall Tests in Experiment 1

\begin{tabular}{|c|c|c|c|c|c|c|}
\hline \multirow{4}{*}{$\begin{array}{c}\text { Encoding } \\
\text { Group }\end{array}$} & \multicolumn{6}{|c|}{ Type of Test } \\
\hline & \multicolumn{4}{|c|}{$\begin{array}{l}\text { Category-Cued } \\
\text { Generation }\end{array}$} & \multirow{2}{*}{\multicolumn{2}{|c|}{$\begin{array}{c}\begin{array}{c}\text { Category-Cued } \\
\text { Recall }\end{array} \\
\text { Studied }\end{array}$}} \\
\hline & \multicolumn{2}{|c|}{ Studied } & \multicolumn{2}{|c|}{ Nonstudied } & & \\
\hline & $M$ & $S D$ & $M$ & $S D$ & $M$ & $S D$ \\
\hline \multicolumn{7}{|l|}{ Naming } \\
\hline Pictures & 39.7 & 11.8 & 22.4 & 8.3 & 69.8 & 9.7 \\
\hline Words & 31.7 & 11.5 & 23.4 & 5.8 & 45.4 & 11.1 \\
\hline \multicolumn{7}{|l|}{ Categorizing } \\
\hline Pictures & 29.0 & 7.8 & 24.0 & 5.2 & 49.9 & 14.0 \\
\hline Words & 36.1 & 6.9 & 22.8 & 6.1 & 47.6 & 10.8 \\
\hline
\end{tabular}

words following both encoding conditions. For categorycued generation, one possible outcome consistent with Weldon and Coyote's findings is that priming will not differ for pictures and words in both encoding conditions. An alternative possible outcome, however, is that priming for words and pictures will differ as a function of encoding task.

\section{Method}

Participants. One hundred and twelve students enrolled in introductory psychology courses at Stanford University received either course credit or a $\$ 10$ payment for participation in the present study

Design and Stimulus Materials. Fifty-six participants performed a category-cued generation test and another 56 participants performed a category-cued recall test. For both tests, encoding (word-name, word-categorize, picture-name, picture-categorize) was a between-participants variable. For category-cued generation, item type (studied or nonstudied) was a within-participants variable.

Stimulus materials consisted of words and line drawings of 72 exemplars that ranked low on category typicality from Battig and Montague's (1969) norms of category membership. Line drawings were obtained from the Snodgrass and Vanderwart set (1980). Six exemplars were selected from each of six semantic categories of manufactured items (musical instruments, clothing, kitchen things, vehicles, furniture, and tools) and six semantic categories of natural items (animals, fruits, birds, vegetables, human body parts, and insects). Typicality ranks did not differ for manufactured ( $M=14.0$; $S D=11.8)$ and natural $(M=17.6 ; S D=13.0)$ exemplars $(p=.22)$. Name agreement for pictures did not differ for manufactured $(M=86.5 ; S D=14.8)$ and natural $(M=88.6 ; S D=11.9)$ exemplars $(p=.51)$.

The 72 exemplars were divided into two study lists ( $A$ and $B$ ) each consisting of a total of 36 exemplars; all exemplars belonging to three manufactured and three natural categories were included in one study list and all exemplars belonging to the remaining three manufactured and three natural categories were included in the other study list. Thus, half of the exemplars in each study list referred to a manufactured item and the remaining half referred to a natural item. In each study list, the order of items was pseudorandomized so that there were no more than three consecutive items of the same type (manufactured/natural). For each study list, two forms were created consisting of words and line drawings, respectively. Thus, there were a total of four study lists, a word and picture form of List A and of List B.

For the category-generation test, one test list was created consisting of 12 category names, 6 referring to items in List A and 6 referring to items in List B. For any given participant, six category names were cues for studied items, and the remaining six category names were cues for nonstudied items. Thus, each item was counterbalanced across studied and nonstudied conditions. The order of category cue presentation was pseudorandomized so that there were no more than three cues of the same type (studied/nonstudied/ manufactured/natural).

For the category-cued recall test, two test lists were created, each consisting of six category names referring to items in List $\mathrm{A}$ and six referring to items in List B, respectively. For any given participant, the six category names were cues for the studied items. The order of category-cue presentation was pseudorandomized so that there were no more than three cues of the same type (manufactured/natural).

Procedure. Each participant was assigned randomly to one of four encoding conditions: word-name, word-categorize, picturename, and picture-categorize. Participants were tested individually while they sat facing an Apple Macintosh LCIII monitor. In the study phase, each trial began with the presentation of a fixation cross for $500 \mathrm{msec}$, followed by a lag of $500 \mathrm{msec}$, the target stimulus (word or picture) for $1 \mathrm{sec}$, and then an intertrial interval of $1.5 \mathrm{sec}$. Participants in the word-name and picture-name conditions were instructed to name aloud the word or picture on the screen. Participants in the word-categorize and picture-categorize conditions were instructed to say aloud whether the word or picture on the screen referred to a manufactured or natural object. For all encoding conditions, participants were instructed to respond as quickly and accurately as possible and to guess when unsure of their response. The experimenter recorded the participant's response and initiated the next trial by pressing the space bar.

For the category-cued generation test phase, the category cue name appeared on the screen for $90 \mathrm{sec}$. Participants were instructed to say the first six members of the named category that came to mind as quickly as possible. The experimenter recorded the responses and advanced to the next category cue by pressing the space bar. For the category-cued recall, the trial procedure was similar to that for category-cued generation. However, participants were instructed to say the six members of the named category that they remembered having seen in the earlier study phase. Participants were allowed as much time as they needed to recall.

\section{Results}

A response was scored as correct for either test if it matched exactly or was the plural of a target exemplar. Scoring was conditionalized on correct responses at encoding (fewer than $1 \%$ of responses were discarded). Table 1 shows participants' mean performance.

Data from category-cued generation and cued recall were analyzed separately. For category-cued generation, participants' mean percentage of correct target production was analyzed in a mixed-design analysis of variance (ANOVA) with stimulus form (word, picture) and encoding task (naming, semantic categorization) as betweenparticipants variables and item type (studied, nonstudied) as a within-participants variable. Overall, mean percentage of targets produced did not differ for participants in the word and picture encoding groups (no main effect of stimulus form), or for participants in the naming and categorization encoding groups (no main effect of encoding task; $F<1$ ). Priming was obtained because participants produced more studied than nonstudied exemplars [main effect of item type, $F(1,52)=65.1, p<.001]$. Priming did not differ for participants in the word and picture encoding group because the stimulus form $\times$ item type interaction was not significant ( $p=.92$ ). Priming did not 


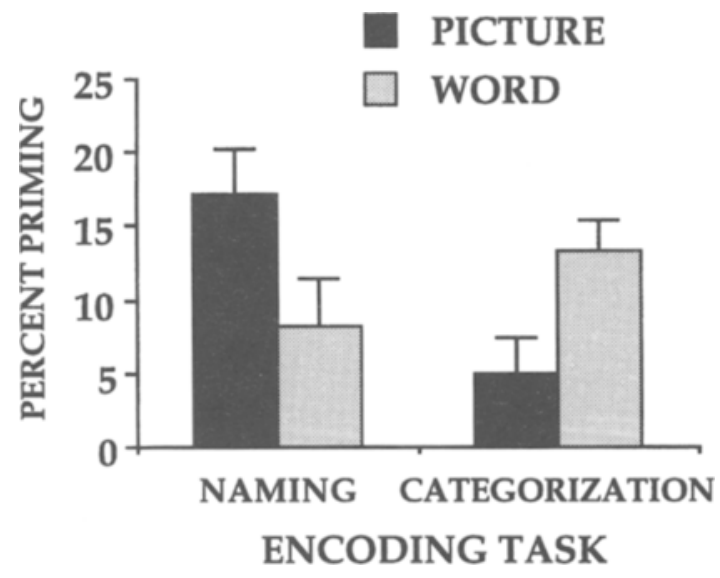

Figure 1. Percentage of priming on category-cued generation as a function of stimulus format (picture, word) and encoding task (naming, categorization) in Experiment 1.

differ for participants in the naming and semantic categorization groups because the encoding task $\times$ item type interaction was not significant $(p=.18)$. Critically, priming differed as a function of the relation between stimulus form and encoding task because the stimulus form $X$ encoding task $\times$ item type interaction was significant $[F(1,52)=10.1, p<.01]$. This interaction did not result from differences in baseline production because it did not differ significantly between the four encoding groups $(t \mathrm{~s}<1)$.

To examine the priming differences suggested by the three-way interaction, priming scores were computed by subtracting the percentage of nonstudied exemplars from the percentage of studied exemplars produced by each participant in each of the four encoding groups (wordname, word-categorize, picture-name, picture-categorize; Figure 1). A one-way ANOVA for single factorial designs confirmed that priming scores differed significantly among the four encoding groups $[F(3,52)=4.0, p=.01]$. Post hoc Fisher's PLSD tests with a significance level of .05 (critical difference $7.7 \%$ ) indicated that priming was significantly greater in the picture-name group $(M=$ $17.2 \%)$ than in the picture-categorize group $(M=5.0 \%)$ and in the word-name group $(M=8.3 \%)$, but not in the word-categorize group $(M=13.3 \%)$. Further, priming was significantly greater in the word-categorize group than in the picture-categorize group, but not in the wordname group.

For category-cued recall, percentage of target exemplars recalled was analyzed in a between-participants ANOVA with two variables, stimulus form (word, picture) and encoding task (naming, semantic categorization). Percentage recall was greater for participants in the picture encoding groups than for those in the word encoding groups [main effect of stimulus form, $F(1,52)=$ $18.5, p<.0001]$. Percentage recall was greater for participants in the naming groups than for those in the semantic encoding groups [main effect of encoding task, $F(1,52)=$
$8.2, p<.01]$. Recall performance differed in the four encoding groups (word-name, word-categorize, picturename, picture-categorize) because the stimulus form $X$ encoding task interaction was significant $[F(1,52)=$ $12.8, p>.001]$. This finding was confirmed by a oneway ANOVA for factorial designs $[F(3,52)=13.2, p<$ $.0001]$, and post hoc Fisher's PLSD tests with a significance level of .05 (critical difference $8.8 \%$ ) indicated that recall was greater in the picture-name group $(M=69.7 \%)$ than in the remaining three encoding groups, picturecategorize $(M=49.8 \%)$, word-categorize $(M=47.6 \%)$, and word-name $(M=45.4 \%)$; these three encoding groups did not differ significantly from each other.

\section{Discussion}

The results of Experiment 1 indicate dissociable effects of encoding task on priming for pictures and words. On category-cued generation, a picture superiority effect was obtained following naming, but a word superiority effect was obtained following semantic categorization. On category-cued recall, a picture superiority effect was obtained following naming, but neither picture nor word superiority was obtained following semantic categorization. Thus, encoding tasks had dissociative effects for pictures and words on both conceptual priming and explicit memory.

Our findings extend those of Weldon and Coyote (1996) in several ways. First, our findings suggest that the lack of picture superiority in conceptual priming in their study was due to open-ended encoding instructions: Participants were simply asked to pay attention to the pictures and words. On the basis of our findings, participants who spontaneously named the stimuli in their study would show picture superiority, but those who spontaneously semantically classified them would show word superiority. If half of Weldon and Coyote's participants engaged in each of the two strategies, these two opposing effects would sum to equal priming for pictures and words. Second, our findings from the cued-recall test extend those of Weldon and Coyote's by specifying the conditions that yield picture superiority: Recall for named pictures $(70 \%)$ was substantially higher than for words or pictures in any other condition $(45 \%-50 \%)$. Thus, their participants who spontaneously named the stimuli would show a picture superiority effect, and their participants who spontaneously categorized the stimuli would show neither picture nor word superiority. These two effects, in light of the present findings, would indeed sum to the result observed in Weldon and Coyote's study, an overall picture superiority effect.

The present findings provide evidence for the dissociability of conceptual processes operating during categorycued recall and category-cued generation. Both tests were matched on test cues and the number of to-be-produced targets; they differed in the inclusion of a baseline production measure (only for generation) and most importantly in retrieval instructions. Test performance was dissociated on two counts. First, word superiority in priming 
Table 2

Mean Reaction Times (and Standard Deviations, in Milliseconds) for Studied and Nonstudied Items on Category-Cued Verification in Experiment 2

\begin{tabular}{|c|c|c|c|c|c|c|c|c|}
\hline \multirow[b]{4}{*}{ Group } & \multicolumn{8}{|c|}{ Type of Item } \\
\hline & \multicolumn{4}{|c|}{ Studied } & \multicolumn{4}{|c|}{ Nonstudied } \\
\hline & \multicolumn{2}{|c|}{ "Yes" } & \multicolumn{2}{|c|}{ "No" } & \multicolumn{2}{|c|}{ "Yes" } & \multicolumn{2}{|c|}{ "No" } \\
\hline & $M$ & $S D$ & $M$ & $S D$ & $M$ & $S D$ & $M$ & $S D$ \\
\hline \multicolumn{9}{|l|}{$\overline{\text { Naming }}$} \\
\hline Pictures & 764 & 134 & 783 & 120 & 798 & 143 & 779 & 125 \\
\hline Words & 741 & 96 & 776 & 95 & 775 & 87 & 799 & 101 \\
\hline \multicolumn{9}{|c|}{ Categorizing } \\
\hline Pictures & 740 & 91 & 762 & 103 & 768 & 104 & 775 & 103 \\
\hline Words & 747 & 106 & 770 & 84 & 778 & 116 & 792 & 122 \\
\hline
\end{tabular}

following semantic categorization instructions did not extend to cued recall; categorized words and pictures were remembered equally well. Second, named pictures were recalled far better than any other encoding conditions. In contrast, for priming, named pictures and semantically categorized words were functionally equivalent. The robust advantage of naming pictures on recall raises the possibility that different conceptual information about pictures may be brought to bear during implicit and explicit memory performance. Perhaps, as suggested by Weldon and Coyote (1996), visual distinctiveness of pictures affects recall but not priming, suggesting that additional conceptual processes are relevant for explicit memory in general or cued recall in particular.

\section{EXPERIMENT 2}

In this experiment, we examined the effects of naming and semantically categorizing words and on another conceptual priming test, category-cued verification. This test is similar to category-cued generation in the type of conceptual knowledge that is probed, semantic category membership. Because the two tests engage the same conceptual knowledge, it is reasonable to expect that, similar to category-cued generation priming, a picture superiority effect will occur following naming, and a word superiority effect, will occur following semantic categorization, on category-verification priming.

Alternatively, findings from category-cued generation may not extend to category-cued verification because the two tests differ in sensitivity to conceptual elaborative encoding manipulations; semantic processing enhanced priming on generation but not verification (Vaidya et al., 1997). Thus, if cued-verification is insensitive to conceptual encoding, priming should not differ for pictures and words in any encoding condition.

\section{Method}

Participants. One hundred and four students enrolled in introductory psychology courses at Stanford University received either course credit or a $\$ 10$ payment for participation in the present study.

Design and Stimulus Materials. Encoding (word-name, wordcategorize, picture-name, picture-categorize) was a between- participants variable, and item type (studied or nonstudied) was a within-participants variable

Stimulus materials were the same as those in Experiment 1. Study lists were the same as those used in Experiment 1. Thus, there were two study lists, each with two forms consisting of words and pictures, respectively. One category verification test list consisting of 72 words was created by combining the exemplars from each of the two study lists. Half of the words (e.g., banana) from each study list were assigned a category verification question that named the semantic category of the word and therefore could be answered with a "yes" response ("Is this a type of fruit?"); the remaining words were assigned a category verification question that named a different semantic category from that of the word and therefore could be answered with a "no" response ("Is this a type of animal?"). Two forms of the category verification test list were created so that for each word, the category verification answer was "yes" on one form and "no" on the other form. For any given participant, half the test words were studied, and the remaining half were nonstudied. Items were counterbalanced across studied and nonstudied conditions. The order of presentation of words was pseudorandomized with the constraint that there were no more than three consecutive trials of the same type (i.e., studied/nonstudied, yes/no).

Procedure. Each participant was assigned randomly to one of four encoding conditions (word-name, word-categorize, picturename, picture-categorize). Participants were tested individually while they sat facing an Apple Macintosh LCIII monitor. The study phase trial procedure was the same as that in Experiment 1. In the test phase, each trial began with the presentation of a fixation dot for $500 \mathrm{msec}$, followed by a lag of $500 \mathrm{msec}$, the category verification question for $2 \mathrm{sec}$ followed immediately by the target word. The target word remained on the screen until participants said "yes" or "no" into the microphone. Participants were instructed to say "yes" if the word on the screen belonged to the semantic category named in the verification question, or "no" if the word on the screen did not belong to the semantic category named in the verification question. Participants' response triggered a voice-activated relay that recorded response times (RTs) to the nearest millisecond. There was an intertrial interval of $500 \mathrm{msec}$. The experimenter recorded participants" "yes" or "no" responses by pressing either the "Y" or "N" key, respectively.

\section{Results}

Mean errors and median RTs for correct "yes" and "no" category verification responses were computed for each participant. Correct responses were conditionalized on correct study phase naming performance (fewer than $1 \%$ of responses were discarded). Error rates were low (fewer than 3\%) and thus were not statistically analyzed. Table 2 shows participants' mean category verification performance.

Participants' median RTs were analyzed in a mixed ANOVA with stimulus form (word, picture) and encoding task (naming, semantic categorization) as betweenparticipants variables and item type (studied, nonstudied) and response type (yes, no) as within-participants variables. Priming was obtained because participants were faster to answer verification questions about studied items than those about nonstudied items [main effect of item type, $F(1,100)=27.3, p<.0001]$. Participants were faster to respond "yes" than "no" [main effect of response type, $F(1,100)=10.6, p<.01]$. "Yes" and "no" RTs differed for studied and nonstudied items [item type $\times$ response type interaction, $F(1,100)=8.84, p<.01]$. Prim- 


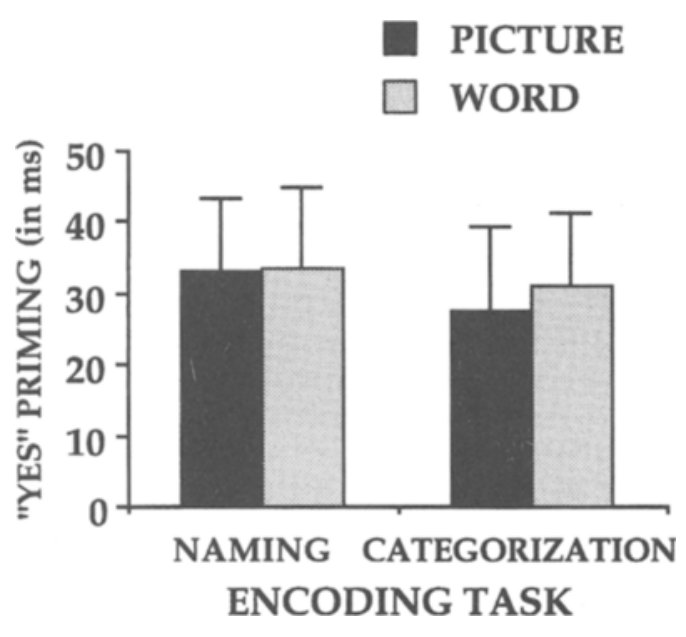

Figure 2. Priming (in milliseconds) for "yes" responses on category-cued verification as a function of stimulus format (picture, word) and encoding task (naming, categorization) in Experiment 2.

ing was significantly greater for "yes" responses than for "no" responses $[t(103)=3.0, p<.01]$. No other main effects or interactions approached significance.

\section{Discussion}

Neither picture nor word superiority was obtained on category-cued verification; priming for "yes" responses did not differ reliably after naming pictures $(33 \mathrm{msec})$, naming words ( $34 \mathrm{msec})$, categorizing pictures $(28 \mathrm{msec}$ ), and categorizing words $(31 \mathrm{msec}$ ) (Figure 2$)$. Priming was significantly reduced for "no" relative to "yes" verification responses. Reduction or elimination of priming for "no" responses is a common phenomenon on the categorycued verification test (Vaidya et al., 1997, Experiment 6) as well as on other tests, such as lexical decision (M. E. Smith \& Oscar-Berman, 1990). Most importantly, however, the magnitude of priming for "yes" and "no" verification responses did not vary by stimulus format or encoding condition.

The present finding of an absence of picture or word superiority in category-verification priming indicates that such priming is insensitive to differences in conceptual encoding. This finding is consistent with a prior study showing that category-verification priming is insensitive to manipulation of levels of semantic encoding (Vaidya et al., 1997). One reason for its immunity to conceptual manipulations may be that perceptual processes contribute substantially to category-verification priming. Hypothetically, verification priming could reflect faster perceptual decoding of repeated words in the test phase. However, two pieces of evidence indicate that this is not so. First, in the present study, the study-test match in visual form was greatest in the word condition; if priming was a product of perceptual processing, then naming or categorizing words should have produced greater prim- ing than the picture conditions. Second, in a past study, study-test modality changes (auditory-study, visual-test) did not reduce verification-priming (Vaidya et al., 1997). Thus, priming on category-cued verification cannot be a product of perceptual processes.

\section{GENERAL DISCUSSION}

The present study yielded three main findings. First, on category-cued generation, a picture superiority effect was obtained following naming and a word superiority effect was obtained following semantic categorization. Second, on category-cued verification, neither picture nor word superiority was obtained following any encoding condition; priming did not differ reliably among named pictures, named words, categorized pictures, and categorized words. Third, on category-cued recall, a picture superiority effect was obtained following naming; recall did not differ among named words, categorized pictures, and categorized words. Thus, encoding tasks had dissociative effects on memory for pictures and words on two conceptual-implicit tests and one explicit test.

The present studies were motivated by three questions. First, what encoding processes lead to picture superiority in conceptual-implicit retrieval? Our findings indicate that the answer to this question can be found within the general principle of transfer appropriate processing, which states that memory will be maximal when encoding and retrieval invoke the same processes. Category-cued generation requires the retrieval and selection of specific exemplars on the basis of a conceptual cue (category label). Therefore, naming pictures may lead to more priming than naming words because greater conceptual information needs to be accrued in order to name a picture than to read a word, a fairly automatized activity. Semantically categorizing words may lead to more priming than categorizing pictures because participants must process the specific meaning of exemplars shown as words. For pictures, however, they need not specify the exemplar itself. For example, all pictures with animate features (wings, legs, eyes) can be categorized as natural without distinguishing one exemplar from another (e.g., dog, cat). This is consistent with findings that pictures are named more slowly than they are categorized, and words are categorized more slowly than they are named (Potter \& Faulconer, 1975; E. R. Smith \& Magee, 1980).

A second question that motivated the present experiment was whether unitary processes mediated picture superiority on category-cued generation and verification forms of conceptual priming. Category-cued verification, in contrast to category-cued generation, appears to exemplify a fundamentally different form of conceptualimplicit retrieval. It requires access to conceptual information in order to identify the meaning of the target item, but it does not require selection because the target item is presented. Therefore, on the basis of the principle of transfer appropriate processing, the verification test recapitulates only processes necessary to understand the 
meaning of the target word. The more extensive conceptual processing engaged during picture naming and word categorization may not be entirely reengaged during verification, and therefore, pictures or words gain no advantage over each other.

It appears that mere exposure to the target word at encoding is enough to yield full priming on verification tests. Indeed, verification priming did not differ following abstract/concrete classification and uppercase/lowercase classification (Vaidya et al., 1997), although these conditions differ considerably in the amount of conceptual processing they entail. This finding is also obtained with another verification test, abstract/concrete classification, which requires verifying whether the presented word is abstract or concrete (Vaidya et al., 1997). Furthermore, encoding words under divided attention conditions yielded as much verification priming as under full-attention conditions (Gabrieli et al., 1999; Light et al., 2000). Categorycued generation priming, however, was reduced under divided-attention encoding. The apparent insensitivity of verification priming to encoding manipulations is further demonstrated by findings from patients with Alzheimer's disease who have impaired conceptual encoding abilities: Priming was intact on category-cued verification but impaired on category-cued generation (Gabrieli et al., 1999). Thus, separate psychological and neural priming mechanisms appear to mediate verification and generation forms of conceptual-implicit retrieval.

One distinction between verification and generation in conceptual-implicit retrieval is that the two measures differ in the amount of response competition they elicit. On the generation test, multiple responses will be activated that fit the criteria specified by the response cue (i.e., category name). In order to be selected, a response that is aided by more extensive conceptual encoding, affords a greater chance for selection. However, on verification tests, there is no response competition. The target word, by virtue of being provided at test, has been selected already. It requires mere identification and access to meaning, and a prior exposure to the target word in any form is sufficient to yield a priming advantage. Differing response competition for the two conceptual-implicit measures may contribute to the observed dissociation.

The third question that motivated the present research was whether unitary processes underlie picture superiority in conceptual-implicit and explicit retrieval. Our findings indicate that naming yields picture superiority on cued recall and on one conceptual-implicit test, categorycued generation. This finding is consistent with other encoding manipulations that similarly affect these two memory tests: Both are (1) enhanced by semantic processing (Hamann, 1990; Srinivas \& Roediger, 1990; Vaidya et al., 1997) and categorical blocking (Rappold \& Hashtroudi, 1991) and (2) reduced by division of attention at encoding (Gabrieli et al., 1999; Mulligan \& Hartman, 1996) and neocortical degeneration of Alzheimer's disease (Monti et al., 1996). However, these two forms of memory were dissociated following semantic categorization: Words yielded more priming than pictures, but both words and pictures were recalled equally well. Two other dissociations have been reported. First, the order in which studied and nonstudied exemplars are produced at test differs on cued generation and cued recall: The first three exemplars produced on the implicit test are not targets (which are atypical exemplars), but prototypical exemplars for the category, whereas those on the explicit tests are target exemplars (Rappold \& Hashtroudi, 1991). Second, conceptual repetition (encoding a word followed immediately by its picture) improves free recall but not categorycued generation priming (McDermott \& Roediger, 1996). Thus, picture superiority may be mediated by similar processes on conceptual-implicit and explicit tests, but other behavioral manipulations reveal psychologically distinct conceptual processes underlying these two forms of conceptual memory.

Evidence for the neural dissociability of explicit and conceptual-implicit retrieval comes from studies with neurologically impaired patients and with normal individuals. Patients with global amnesia have damage to the medial temporal lobes or diencephalic regions and show impaired explicit retrieval for pictures and words but intact conceptual-implicit retrieval by a variety of measures (Keane et al., 1997; Vaidya, Gabrieli, Keane, \& Monti, 1995). Thus, distinct brain regions subserve these two forms of retrieval, a finding that is also supported by brain imaging studies of normal individuals. Not only are distinct brain regions recruited for the two types of retrieval-left-frontal for verbal conceptual-implicit retrieval, and right-frontal for verbal explicit retrieval (Poldrack \& Gabrieli, 1998) - but also the neural signatures differ for the two forms of memory. Implicit retrieval is associated with reduced activation for repeated experiences, whereas explicit retrieval is associated with increased activation for remembrance of prior experiences. Thus, explicit and conceptual-implicit retrieval are distinguished in the brain.

In conclusion, these studies show that an interaction between stimulus form and encoding task determines what knowledge is encoded at study, and that dissociable forms of conceptual memory retrieval benefit differentially from that interaction.

\section{REFERENCES}

Battig, W. F., \& Montague, W. E. (1969). Category norms of verbal items in 56 categories: A replication and extension of the Connecticut category norms. Journal of Experimental Psychology Monographs, 80, (3, Pt. 2).

Borges, M. A., Stepnowsky, M. A., \& Holt, L. H. (1977). Recall and recognition of words and pictures by adults and children. Bulletin of the Psychonomic Society, 9, 113-114.

Craik, F. I. M., \& Lockhart, R. S. (1972). Levels of processing: A framework for memory research. Journal of Verbal Learning \& Verbal Behavior, 11, 671-684.

Durso, F. T., \& JoHnson, M. K. (1980). The effects of orienting tasks on recognition, recall, and modality confusion of pictures and words. Journal of Verbal Learning \& Verbal Behavior, 19, 416-429.

Gabrieli, J. D. E., Vaidya, C. J., Stone, M., Francis, W. S., ThompsonSchill, S. L., Fleischman, D. A., Tinklenberg, J. R.. Yesavage, 
J. A., \& WILSON, R. S. (1999). Convergent behavioral and neuropsychological evidence for a distinction between identification and production forms of repetition priming. Journal of Experimental Psychology: General, 128, 479-498.

GRAF, P., \& SCHACTER, D. L. (1985), Implicit and explicit memory for new associations in normal and amnesic subjects. Journal of Experimental Psychology: Learning, Memory, \& Cognition, 11, 501-518.

HaMANN, S. B. (1990). Level-of-processing effects in conceptually driven implicit tasks. Journal of Experimental Psychology: Learning, Memory, \& Cognition, 16, 970-977.

Keane, M. M., Gabrieli, J. D. E., Monti, L. A., Fleischman, D. A., Cantor, J. M., \& Noland, J. S. (1997). Intact and impaired conceptual memory processes in amnesia. Neuropsychology, 11, 59-69.

Kirsner, K., Milech, D., \& StumpFel, V. (1986). Word and picture identification: Is representational parsimony possible? Memory \& Cognition, 14, 398-408.

Lachman, R., \& LaChman, J. L. (1980). Picture naming: Retrieval and activation of long-term memory. In L. W. Poon, J. L. Fozard, L. S. Cermak, D. Arenberg, \& L. W. Thompson (Eds.), New Directions in Memory and Aging: Proceedings of the George A. Talland Memorial Conference (pp. 313-343). Hillsdale, NJ: Erlbaum.

Light, L. L., Prull, M. W., \& KenNison, R. F. (2000). Divided attention, aging, and priming in exemplar generation and semantic verification. Manuscript submitted for publication.

Madigan, S. (1983). Picture memory. In J. C. Yuille (Ed.), Imagery. memory and cognition: Essays in honor of Allan Paivio (pp. 65-89) Hillsdale, NJ: Erlbaum.

MCDermott, K. B., \& Roediger, H. L., III ( 1996). Exact and conceptual repetition dissociate conceptual memory tests: Problems for transfer appropriate processing theory. Canadian Journal of Experimental Psychology, 50, 57-71.

Monti, L. A., Gabrieli, J. D. E., Reminger, S. L., Rinaldi, J. A., WilSON, R. S., \& FleisChMAN, D. A. (1996). Differential effects of aging and Alzheimer's disease upon conceptual implicit and explicit memory. Neuropsychology, 10, 101-112.

Morris, D. C., Bransford, J. D., \& FranKs, J. J. (1977). Levels of processing versus transfer appropriate processing. Journal of Verbal Learning \& Verbal Behavior, 16, 519-533.

Mulligan, N. W., \& Hartman, M. (1996). Divided attention and indirect memory tests. Memory \& Cognition, 24, 453-465.

Nelson, D. L. (1979). Remembering pictures and words: Appearance, significance, and name. In L. S. Cermak \& F. I. M. Craik (Eds.) Levels of processing in human memory (pp. 45-76). Hillsdale, $\mathrm{NJ}$ Erlbaum.

PaIvio, A. (1986). Mental representation: A dual coding approach. Hillsdale, NJ: Erlbaum

Paivio, A., Rogers, T. B., \& Smythe, P. C. (1968). Why are pictures easier to recall than words? Psychonomic Science, 11, 137-138.

Park, S. M., \& Gabrieli, J. D. E. (1995). Perceptual and nonperceptual components of implicit memory for pictures, Journal of Experimental Psychology: Learning, Memory. \& Cognition, 21, 1583-1594.

POLDRACK, R. A., \& GABRIELI, J. D. E. (1998). Memory and the brain What's right and what's left? Cell, 93, 1091-1093.

Potter, M. C., \& Faulconer, B. A. (1975). Time to understand pictures and words. Nature, 253, 437-438.
Rajaram, S., \& Roediger, H. L., III (1993). Direct comparison of four implicit memory tests. Journal of Experimental Psychology: Learning, Memory, \& Cognition, 19, 765-776.

RaPpold, V. A., \& HaShTroudi, S. (1991). Does organization improve priming? Journal of Experimental Psychology: Learning. Memory, \& Cognition, 17, 103-114

Scarborough, D. L.. Gerard, L., \& Cortese, C. (1979). Accessing lexical memory: The transfer of word repetition effects across task and modality. Memory \& Cognition, 7, 3-12.

SCHACTER, D. L., \& MCGLynN, S. M. (1989). Implicit memory: Effects of elaboration depend on unitization. American Journal of Psychology, 102, 151-181.

Slamecka, N. J., \& Graf, P. (1978). The generation effect: Delineation of a phenomenon. Journal of Experimental Psychology: Human Learning \& Memory, 4, 492-604.

Smith, E. R., \& Magee, L. E. (1980). Tracing the time course of picture-word processing. Journal of Experimental Psychology: General, 109, 373-392.

Smith, M. E., \& OsCar-Berman, M. (1990). Repetition priming of words and pseudowords in divided attention. Journal of Experimental Psychology: Learning, Memory, \& Cognition, 16, 1033-1042.

SnOdgrass, J. G., \& VANDERWART, M. (1980). A standardized set of 260 pictures: Norms for name agreement, image agreement, familiarity, and visual complexity. Journal of Experimental Psychology: Learning, Memory, \& Cognition, 6, 174-215.

SRINIVAS, K. (1993). Perceptual specificity in nonverbal priming. Journal of Experimental Psychology: Learning, Memory. \& Cognition, 19, 582-602.

SRINIVAS, K., \& Roediger, H. L., III (1990). Classifying implicit memory tests: Category association and anagram solution. Journal of Memory \& Language, 29, 389-412.

Vaidya, C. J., Gabrieli, J. D. E., Keane, M. M., \& Monti, L. A. (1995). Perceptual and conceptual memory processes in global amnesia. Neuropsychology, 9, 580-59I.

Vaidya, C. J., Gabrieli, J. D. E., Keane, M. M.. Monti, L. A., Gutierrez-Rivas, H., \& Zarella, M. M. (1997). Evidence for multiple mechanisms of conceptual priming on implicit memory tests. Journal of Experimental Psychology: Learning, Memory, \& Cognition, 23, 1324-1343.

WARren, C., \& MorTon, J. (1982). The effects of priming on picture recognition. British Journal of Psychology, 73, 117-129.

WELDON, M. S., \& COYOTE, K. C. (1996). Failure to find the picture superiority effect in implicit conceptual memory tests. Journal of Experimental Psychology: Learning, Memory, \& Cognition, 22, 670-686.

WELDON, M. S., \& RoEDIGER, H. L., III (1987). Altering retrieval demands reverses the picture superiority effect. Memory \& Cognition, 15, 269-280.

WinNiCK, W. A., \& DANIEL, S. A. (1970). Two kinds of response priming in tachistoscopic word recognition. Journal of Experimental Psychology, 84, 74-81.

(Manuscript received August 10, 1998 ; revision accepted for publication Decmber 29, 1999. ) 